clinical, physiological and social psychological research and provides an exhaustive bibliography. The result is a very substantial and stimulating work which, although unsuitable as a basic textbook for students, provides an excellent reference book and exciting theoretical standpoint both for clinicians and academics.

\section{Paediatric Emergencies}

Edited by J. A. Black. Pp. xvi +874 , illustrated. Butterworths, London, Boston, etc., 1979. $£ 29.00$.

There is no substitute for prior experience and the understanding of first principles in the management of paediatric or indeed any medical emergency. Often it is the most junior on-site member of the paediatric team, alone at night, or with senior support not immediately available, who is left to deal with what is to him a frightening and often very dangerous situation. He may have little time to resort to the books or the telephone in search of support and advice. The ideal method of teaching medical students and junior house staff this type of medicine has not yet been devised. A textbook is far from ideal yet in the first instance may be the only source of information.

Paediatric Emergencies provides a comprehensive reference text with individual problems outlined concisely but yet in adequate detail. An international list of contributors author the individual chapters, and the basic style is retained throughout. The contents are complete and cover not only the common traumatic and cardio-respiratory emergencies but also the less commonly encountered problems such as tropical and medico-social disorders. The appendix gives useful information such as drug interactions, dosage of commonly used drugs and the composition of various intravenous solutions. There are only 2 faults, one is the book's size-it cannot be easily carried in one's pocket for immediate reference and, secondly, there is a general paucity of diagrams and visual aids. The book is useful to the doctor with limited paediatric experience but who might be called upon to see sick children. A copy should be available in all casualty departments where children are, or may be, seen.

\section{The Selection of Essential Drugs}

Second report of the WHO Expert Committee. WHO Technical Report Series 641. Pp. 44. World Health Organization, Geneva, 1980. Sw. fr. 3.00 .

Those of us who are familiar with the plethora of drug products available in Europe and North America may not realize what problems our medical colleagues in less developed parts of the world experience in obtaining medicines appropriate for common and often potentially serious diseases. In 1977 a list was published by the WHO which might be considered as a selection of essential drugs to be given priority by national health authorities in such less fortunate parts of the world and, although it received the expected criticism from several sources, there was a widespread acceptance of the need for such impartial authoritative advice. The WHO Expert Committee has now produced this second report which includes some minor amendments to its explanatory notes, updates the list of recommended preparations, and deletes some which are considered inferior in certain respects to those drugs now recommended for inclusion. The WHO is to be congratulated on this enterprise and encouraged to call its expert committee together at regular and frequent intervals so that this extremely valuable document can be kept up-to-date and relevant, thus ensuring that all national authorities can at least be aware of the most appropriate drug treatments available for their important health problems.

\section{A Short Textbook of Clinical Oncology}

By R. D. Rubens and R. K. KNIGHT. Pp. 182, illustrated. Hodder and Stoughton, London, Sydney, Auckland and Toronto, 1980 . hardback, $£ 6.00$ paperback, $£ 2.95$.

This book is written for the undergraduate and the postgraduate who need a brief introduction to the subject. It deals first with some general principles covering the biology of cancer, epidemiology, assessment of the cancer patient and the principles of therapy. It then discusses in more detail the features of various malignant diseases and ends with a discussion of general medical aspects.

Throughout, the book is written in a lucid style and it is well balanced. A book of this size has to be non-controversial but current practice is given in sufficient detail to be useful There are some recommendations that might be questioned such as the use of mercaptopurine or methotrexate as maintenance therapy for acute lymphoblastic leukaemia when it is usual to employ a combination of these drugs. There is probably some risk in not staging by laparotomy even stage 1 lymphocyte predominant Hodgkin's disease and no mention is made of the dangers of laparotomy with splenectomy in children.

The book can be recommended as a valuable addition to the smaller books now available on oncology.

\section{Surgery of the Anus, Rectum and Colon}

By J. C. Goligher with the collaboration of H. L. Duthio and H. H. NixON. 4th edn. Pp. vii +968 , illustrated. Baillière Tindall, London, 1980. $£ 35.00$.

Anyone who has had the experience of writing a surgical textbook will feel humble when he reads through Professor Goligher's classical magnum opus on surgery of the large bowel. Apart from contributions by Professor Duthie on anatomy and physiology, and by $\mathrm{Mr}$ Harold Nixon on congenital anorectal abnormalities and on large bowel aganglionosis, it represents that rarity in today's medical publishing-a one-man show. Magnificently written, profusely and beautifully illustrated (with many excellent drawings by Mr Robert Lane) and with extensive and upto-date bibliographic reviews, it represents undoubtedly the standard source book of information in this field in the English language.

The 4th edition has been extensively revised, with the chapter on Crohn's disease largely rewritten. There are new sections on the technique of the various forms of sphinctersaving operations in resection of the rectum with a detailed account of the new stapling guns for construction of the anastomoses, recent innovations in the surgery and aftercare of enterostomas, including the magnetic ring-closing device for colostomies and the reservoir ileostomy, and the possible place of ileo-anal pull-through anastomosis, with or without an ileal pouch, in the treatment of ulcerative colitis.

Perhaps the most important feature of the book, and certainly the one that gives it its greatest appeal to practising surgeons, is that John Goligher, having discussed all the available modalities of treatment, will then give his personal advice and current practice, together with the cogent arguments in their favour. Reading his book is the next best thing to having him standing beside you at a consultation! This is certainly a book that every surgeon who has to deal with colonic and ano-rectal problems will need on his bookshelf. 